\title{
ANÁLISE DISCURSIVO-CRÍTICA DO PROJETO DE LEI Nº 435, DE 2019
}

\author{
(Discursive-critical analysis of Law Project no. 435, 2019)
}

\author{
Kênia Lara da Silva ${ }^{1}$ \\ (Universidade Federal de Minas Gerais) \\ Rafaela Siqueira Costa Schreck ${ }^{2}$ \\ (Universidade Federal de Minas Gerais) \\ Maria Carmen Aires Gomes ${ }^{3}$ \\ (Universidade Federal de Viçosa)
}

\begin{abstract}
RESUMO
Este artigo tem como objetivo analisar a maneira como as ideologias operam nas construções discursivas produzidas, identificado na Justificativa do Projeto de Lei 435/2019. Para tanto, serão analisados modos de operação de ideologia, conforme propostos por Thompson (2011). O Projeto de Lei é um tipo de gênero discursivo resultado de uma prática sociodiscursiva jurídico-política, portanto um modo de agir e interagir discursivamente. A metodologia da Análise Discursivo-Crítica permitiu identificar as estratégias linguísticostextuais e os modos de operação da ideologia contrários ao parto normal, sendo os mais recorrentes Dissimulação, Fragmentação, Reificação e Legitimação.
\end{abstract}

Palavras-chave: Parto Normal. ADC. Modos de Operação de Ideologia.

\begin{abstract}
This article aims to analyze the way in which ideologies operate in the discursive constructions produced, identified in the Justification of Bill 435/2019. For that, ideology operating modes will be analyzed, as proposed by Thompson (2011). The Bill is a type of discursive genre resulting from a socio-discursive legalpolitical practice, therefore a way of acting and interacting discursively. The methodology of DiscursiveCritical Analysis allowed to identify the linguistic-textual strategies and the modes of operation of the ideology contrary to normal childbirth, being the most recurrent Dissimulation, Fragmentation, Reification and Legitimation.
\end{abstract}

Keywords: Normal birth. ADC. Ideology Operating Modes.

\section{RESUMEN}

Este artículo tiene como objetivo analizar la forma en que operan las ideologías en las construcciones discursivas producidas, identificadas en la Justificación del Proyecto de Ley 435/2019. Para eso, se analizarán los modos operativos de ideología, tal como lo propuso Thompson (2011). El proyecto de ley es un tipo de género discursivo que resulta de una práctica sociopolítica socio-discursiva, por lo tanto, una forma

\footnotetext{
${ }^{1}$ Doutora e Mestre em Enfermagem pela Escola de Enfermagem da Universidade Federal de Minas Gerais (UFMG). Professora associada da Escola de Enfermagem UFMG. Professora do Programa de Pós-graduação em Enfermagem UFMG. Pesquisadora coordenadora do Núcleo de Estudos e Pesquisas sobre Ensino e Prática de Enfermagem (NUPEPE). E-mail: kenialara17@gmail.com

${ }^{2}$ Doutoranda e Mestre em Enfermagem pela Escola de Enfermagem da Universidade Federal de Minas Gerais (UFMG). Enfermeira Obstétrica. Membro do Núcleo de Estudos e Pesquisas sobre Ensino e Prática de Enfermagem (NUPEPE). E-mail: rafaelasiqcosta@yahoo.com.br

${ }^{3}$ Doutora e Mestre em Estudos Lingüísticos/Análise do Discurso, pela Universidade Federal de Minas Gerais (UFMG). Professora associada da Universidade Federal de Viçosa (UFV) com experiência na área de Estudos do Texto e do Discurso. E-mail: mcgomes@ufv.br
} 
de actuar e interactuar discursivamente. La metodología del Análisis Discursivo-Crítico permitió identificar las estrategias lingüísticas-textuales y los modos de operación de la ideología contraria al parto normal, siendo los más recurrentes el Ocultamiento, la Fragmentación, la Reificación y la Legitimación.

Palabras clave: Nacimiento normal ADC. Ideología Modos operativos.

Recebido em: abril 2020

Aceito em: maio 2020

DOI: $10.26512 /$ les.v21i1.31026

\section{INTRODUÇÃO}

O nascimento de uma criança, tradicionalmente, era considerado um momento de exclusiva vivência feminina, centrado no ambiente familiar e com a presença de parteiras para a assistência necessária. No entanto, ao longo dos anos, principalmente, nas últimas décadas, ocorreram transformações significativas na atenção à saúde da mulher durante o ciclo gravídico-puerperal, influenciadas, principalmente, pelo modelo biomédico, hospitalocêntrico e tecnológico no parto e no nascimento (DUARTE et.al., 2019).

Atualmente, os benefícios do parto normal para o binômio mãe-filho são apontados amplamente pela Organização Mundial de Saúde (OMS), ao afirmar que o nascimento é um processo fisiológico e deve ser respeitado, principalmente com a redução de intervenções, ações de empoderamento da mulher e a capacitação dos profissionais para uma assistência segura e de qualidade. A OMS defende que a cesárea possui riscos maternos e fetais e, portanto, deve ser realizada apenas em casos de indicação clínica.

O Brasil enfrenta, nas últimas décadas, uma epidemia de cesáreas, e está entre os países com o maior número desse tipo de cirurgia no mundo. A cada 10 partos realizados em maternidades particulares no Brasil, 8,5 são cesáreas, sendo que a OMS recomenda 1,5. Este elevado número de cesarianas, resultado da perda da autonomia da mulher no processo de parturição e de uma cultura médica intervencionista na assistência aos nascimentos, deve-se à ideia de que o parto deve ser medicalizado ou tratado, o que tem acarretado aumento na taxa de morbimortalidade materna e perinatal, sobrecarregando os sistemas social e financeiro do país (KOTTWITZ; GOUVEIA, GONÇALVES, 2018; VEJA; SOARES; NASR, 2017; WHO, 2015; TORRES et. al., 2014).

Os indicadores de saúde relacionados à assistência obstétrica, no país, são alarmantes. Uma cadeia de eventos ocasiona sua ocorrência tais como: as características socioculturais e econômicas da população, políticas de saúde, iniquidade e exclusão. A taxa de mortalidade materna é muito alta. O uso abusivo de cesárea revela a situação que tem contribuído para a desumanização da assistência, 
e o preparo e a atuação dos profissionais de saúde têm sido alvo de intensos debates (VEGA, SOARES, NASR, 2017; TORRES et. al., 2014; MERIGUI; GUALDA, 2009).

Para a redução dos altos índices de cesariana, e, consequentemente, a diminuição da morbimortalidade materna e neonatal, o Ministério da Saúde e a Agência Nacional de Saúde (ANS) estão implementando uma série de medidas para estimular a realização de partos normais de forma a reduzir o alto índice de cesáreas desnecessárias, no País. Dentre essas medidas, destacam-se a exigência da inclusão do instrumento partograma para o acompanhamento seguro do trabalho de parto e parto normal; garantia que as usuárias de planos de saúde tenham acesso à informação sobre o percentual de partos normais e cesáreas realizados por médico, hospital e operadora; e adoção de programas de incentivo ao nascimento fisiológico, como o Parto Adequado, Política Nacional de Humanização, e de capacitação dos profissionais, como o ApiceOn (BRASIL, 2017).

A trajetória nacional para incentivo ao parto normal e mudança do paradigma tecnocrático para um modelo de atenção humanista e humanizado é resultado da ação de políticas públicas, fóruns perinatais e movimentos sociais, principalmente, feministas. Estes atores defendem a autonomia da mulher no momento de parturição e a medicina baseada em evidências, para redução do uso indiscriminado da tecnologia, das intervenções cirúrgicas, mortalidade materna e prematuridade iatrogênica.

Contudo, há outros movimentos no país que disputam ideologicamente a defesa do modelo de parto e nascimento. Entre estes, cita-se o Projeto de Lei (PL) 435/2019 que surge com a proposta de assegurar à toda gestante a opção pelo parto cesárea, a partir de 39 semanas de gestação, sem indicação clínica. Essa proposta surge no país no momento em que o panorama do parto e nascimento é marcado por disputas acerca do embate do parto: entre partidários do modelo tecnocrático, defensores da cesárea, e do humanístico/humanizado de assistência, ativistas à favor do parto normal (MENDONÇA, 2015). O processo de nascimento no país ainda é caracterizado por grandes desafios, como a violação dos direitos das gestantes, intervenções e iatrogenias obstétricas e neonatais, que são usadas de forma rotineira e não baseadas nas melhores evidências científicas, aumentando os desfechos maternos e perinatais desfavoráveis e os casos de violência obstétrica (LEAL et.al., 2019; LEAL, 2018).

A melhoria das condições de saúde das mulheres brasileiras depende, atualmente, da defesa intransigente dos direitos sociais e de cidadania, da valorização do gênero, e sobretudo, da educação em saúde, redução da pobreza e das iniquidades sociais em saúde (LEAL et.al., 2019; WALL, 2018).

O PL 435/2019 é de autoria da deputada estadual de São Paulo, Janaína Paschoal, advogada e jurista, filiada ao Partido Social Liberal (PSL), com experiência, principalmente, na área de 
docência em Direito Penal. Embora sua formação seja em Direito, a parlamentar atua politicamente nas áreas de Saúde, Educação e Segurança Pública.

Em trâmite na Câmara dos Deputados, o Projeto de Lei, conhecido como "PL da Cesárea", defende, em seu Artigo $1^{\circ}$, que

a parturiente tem direito à cesariana eletiva, devendo ser respeitada em sua autonomia" e "garante à gestante a possibilidade de optar pelo parto cesariano, a partir da trigésima nona semana de gestação, bem como a analgesia, mesmo quando escolhido o parto normal.

Ainda que o presente documento possua características legislativas próprias, o texto foi produzido por uma autoridade legislativa, que possui ideologias partidárias e pessoais que reproduzem diretamente em suas justificativas de Projeto de Lei. O nosso objetivo, neste artigo, é analisar discursivamente este documento, identificando os modos de operação da ideologia, segundo Thompson (2011), produzidos na Justificativa do PL.

Para uma análise crítica do documento, será considerado o princípio do "discurso e da linguagem como o coração das práticas e dos processos sociais” (RESENDE, RAMALHO, 2006).

Assim, baseado nos princípios da metodologia da Análise do Discurso Crítica (ADC), o discurso será analisado de forma tridimensional, identificando o texto e a prática discursiva como dimensões inseridas na prática social, reconhecendo as ideologias, sentidos e orientações hegemônicas presentes. Ressalta-se que a ADC será empregada com o objetivo de não apenas descrever as estruturas do discurso, mas explicá-las em termos de organização social.

Nas seções que se seguem, serão apresentados alguns princípios e fundamentos da abordagem discursivo-crítica utilizada para a análise para, em seguida, configurarmos o gênero discursivo da Justificativa do Projeto de Lei 435/2019, à luz das categorias propostas por Norman Fairclough $(2001,2003)$, identificando as condições da sua produção, a forma como o sujeito é representado discursivamente e a conjuntura social, política e da saúde na emergência desse Projeto de Lei.

\section{PRINCÍPIOS DA ONTOLOGIA DISCURSIVA: RELAÇÕES ENTRE LINGUAGEM E SOCIEDADE}

A análise do Discurso Crítica (ADC) é um campo disciplinar reconhecido internacionalmente, que possui teóricos com estudos sistemáticos, dentre eles Norman Fairclough, com uma série de obras sobre a temática que trazem um método para a análise do discurso (FAIRCLOUGH 1989, 1992, 1995a, 1995b, 2000, 2003). 
Considera-se, de uma maneira geral, o termo discurso como "uma visão particular da linguagem em uso", "um elemento da vida social que é interligado de maneira próxima a outros elementos" (FAIRCLOUGH, 2003, p. 3). A abordagem discursivo-crítica de Fairclough compreende a unidade de análise do texto centrada no discurso como uma forma de ação e representação social, o que significa dizer que agimos discursivamente, como também representamos discursivamente o mundo (social) a que pertencemos.

A escolha por este método de análise textual deu-se pela sua ontologia de posicionamento crítico, emancipatório, que, além da descrição linguístico-textual minuciosa de um documento-objeto, visa à interpretação explanatória crítica dos fenômenos, que se apresentam em instituições sociais, com determinadas formações ideológico-discursivas, e as respectivas relações de poder entre elas.

De acordo com os princípios analíticos propostos por Fairclough em 1989 e aprimorado em 1992, essa abordagem assume que o discurso se constitui de três dimensões: texto, prática discursiva e prática social.

A dimensão de análise do texto compreende o vocabulário, a gramática sistêmico-funcional, coesão e a estrutura textual. A prática discursiva explora os processos de produção, distribuição e consumo do texto, incluindo as categorias de coerência e força dos enunciados, juntamente com a análise das relações dialógicas entre o texto e outros textos (intertextualidade) e das relações entre ordens distintas de discurso (interdiscursividade). Os aspectos ideológicos e hegemônicos estão inseridos no estudo da prática social. Nessa dimensão discursiva, observam-se os elementos textuais que podem ser compreendidos ideologicamente, como o significado das palavras, as pressuposições, as metáforas, o estilo. Os posicionamentos da prática social econômica, política e cultural podem ser observados na categoria de hegemonia (RAMALHO, RESENDE, 2011; RESENDE, RAMALHO, 2006; FAIRCLOUGH, 2001).

A prática discursiva é intermediária entre o texto e a prática social, segundo Fairclough (2001, p. 35-36):

A conexão entre o texto e a prática social é vista como mediada pela prática discursiva: de um lado, os processos de produção e interpretação são formados pela natureza da prática social, ajudando também a formá-la e, por outro lado, o processo de produção forma (e deixa vestígios) no texto, e o processo interpretativo opera sobre 'pistas' no texto.

Portanto, a análise discursivo-crítica permite investigar os focos de luta hegemônica presentes em um texto, contribuindo para a articulação, desarticulação e rearticulação de complexos ideológicos (MAGALHAES, 2005; FAIRCLOUGH, 2001)

A consciência do uso da linguagem como uma prática social permite compreendê-la como um modo de ação sócio-histórico. Dessa forma, o sujeito do discurso, ao moldar a estrutura de suas 
orações, também realiza escolhas sobre o significado (e a construção, manutenção ou subversão) de identidades sociais, relações sociais e conhecimento e crença. A relação entre discurso e estrutura social, portanto, tem natureza complexa e dialética, resultando do contraponto entre a determinação do discurso e sua construção social (PEIXOTO, ALENCAR, FERREIRA, 2018; RESENDE, RAMALHO, 2006; FAIRCLOUGH, 1992).

Nesse estudo, consideramos a concepção crítica de ideologia como forma de investigação social, conforme enunciado por Thompson (2011, p. 97):

De fato, em alguns casos, a ideologia pode operar através do ocultamento e do mascaramento das relações sociais, através do obscurecimento ou da falta de interpretação das situações; mas essas são possibilidades contingentes, e não características necessárias da ideologia como tal. Ao tratar o erro e a ilusão como uma possibilidade contingente, ao invés de como uma característica necessária da ideologia, nós podemos aliviar a análise da ideologia de parte do peso epistemológico colocado sobre ela desde Napoleão. Entretanto, engajar-se na análise da ideologia não pressupõe, necessariamente, que os fenômenos caracterizados como ideológicos foram mostrados, ou podem ser vistos como errôneos ou ilusórios.

A partir desses pressupostos, analisaremos metodologicamente a Justificativa do Projeto de Lei no 435, de 2019, seguindo os modos de operação da Ideologia propostos por Thompson (2011), reproduzidos com as explicações dadas pelo próprio autor no Quadro 1. Os modos gerais e as estratégias de construção simbólica são utilizadas para desmascarar as dinâmicas de dominação presentes na atuação escrita dos autores dos discursos, buscando o convencimento e a efetivação de seus propósitos sociocomunicativos:

\section{Quadro 1 - Modos de Operação Ideológicos}

\begin{tabular}{|l|l|}
\hline \multicolumn{1}{|c|}{ Modos Gerais } & $\begin{array}{c}\text { Algumas Estratégias Típicas de Construção } \\
\text { Simbólica }\end{array}$ \\
\hline $\begin{array}{l}\text { LEGITIMAÇÃO } \\
\text { Relações de dominação são representadas como } \\
\text { legítimas. }\end{array}$ & $\begin{array}{l}\text { Racionalização: uma cadeia de raciocínio } \\
\text { procura justificar um conjunto de relações. } \\
\text { Universalização: interesses específicos são } \\
\text { apresentados como interesses gerais. } \\
\text { Narrativização: exigências de legitimação } \\
\text { inseridas em histórias do passado que legitimam } \\
\text { o presente }\end{array}$ \\
\hline
\end{tabular}




\begin{tabular}{|l|l|}
\hline $\begin{array}{l}\text { DISSIMULAÇÃO } \\
\text { Relações de dominação são ocultas, negadas ou } \\
\text { obscurecidas. }\end{array}$ & $\begin{array}{l}\text { Deslocamento: deslocamento contextual de } \\
\text { termos e expressões. } \\
\text { Eufemização: valorização positiva de } \\
\text { instituições, ações ou relações. } \\
\text { Tropo: sinédoque, metonímia, metáfora }\end{array}$ \\
\hline $\begin{array}{l}\text { UNIFICAÇÃO } \\
\text { Construção simbólica de identidade coletiva }\end{array}$ & $\begin{array}{l}\text { Estandartização: um referencial padrão } \\
\text { proposto como fundamento partilhado. } \\
\text { Simbolização da unidade: construção de } \\
\text { símbolos de unidade e identificação coletiva. }\end{array}$ \\
\hline $\begin{array}{l}\text { FRAGMENTAÇÃO } \\
\text { possam representar ameaça ao grupo dominante. }\end{array}$ & $\begin{array}{l}\text { Diferenciação: ênfase em características que } \\
\text { desunem e impedem a constituição de desafio } \\
\text { efetivo. } \\
\text { Expurgo do outro: construção simbólica de um } \\
\text { inimigo }\end{array}$ \\
\hline $\begin{array}{l}\text { REIFICAÇÃO } \\
\text { Retração de uma situação transitória como } \\
\text { permanente e natural. }\end{array}$ & $\begin{array}{l}\text { Naturalização: criação social e histórica tratada } \\
\text { Eternalização: fenômenos sócio-históricos } \\
\text { como permanentes. } \\
\text { Nominalização/passivação: concentração da } \\
\text { atenção em certos temas em detrimento de } \\
\text { outros, com apagamento de atores e ações. }\end{array}$ \\
\hline
\end{tabular}

Fonte: Thompson (2011)

Norman Fairclough (2001) descreve os modos de operação da Ideologia propostos por Thompson, vinculados ao discurso, como formas relações de poder, com práticas discursivas e ideologias construídas como estratégias de relações de dominação.

Entende-se que essa abordagem é adequada para o objetivo deste estudo analítico-discursivo sobre a Justificativa do Projeto de Lei 435/2019, permitindo relacioná-lo ao contexto da assistência ao parto no Brasil, identificando e mostrando como as ideologias são construídas e operam nas construções discursivas.

A análise discursivo-crítica desse documento faz-se relevante e necessária pela sua repercussão social e potencialidade de impacto nos indicadores de saúde, no país. O PL 435/2019 foi aprovado pela Assembleia Legislativa e está em vigor no estado de São Paulo, o que gerou muitas controvérsias entre os posicionamentos de entidades representativas da Saúde. 
Instituições como a Federação Brasileira das Associações de Ginecologia e Obstetrícia (Febrasgo), a Associação de Obstetrícia e Ginecologia do Estado de São Paulo (SOGESP), o Conselho de Secretários Municipais de Saúde do Estado de São Paulo (COSEMS/SP) e o Conselho Regional de Enfermagem de São Paulo (COREN-SP) manifestaram, por meio de notas técnicas e cartas abertas, a defesa do parto normal e humanizado, solicitando a revogação do PL 435/2019.

Essas instituições reivindicaram à deputada, autora do Projeto de Lei, a revisão do texto e a ampliação da discussão das propostas com profissionais especialistas, considerando evidências científicas e dados epidemiológicos do Estado de São Paulo. No entanto, o Conselho Regional de Medicina do Estado de São Paulo, Cremesp, em posicionamento oficial, defendeu a cesariana à pedido da gestante, criticando os índices ideais de cesárea e vilanização da prática cirúrgica obstétrica no país, endossando o discurso do PL sobre a segurança da vida da mãe e do bebê.

\section{JUSTIFICATIVA DO PROJETO DE LEI No 435, DE 2019: ANÁLISE DISCURSIVO-CRÍTICA}

O gênero discursivo abordado é o de um projeto de lei, cuja temática da realização da cesariana por opção da gestante é descrita a partir do entrecruzamento entre o discurso jurídico, com a presença constante de intertextos e interdiscursos de políticas públicas, e posicionamentos de Órgãos Oficiais da Saúde, como Ministério da Saúde.

A Justificativa do Projeto de Lei (PL) apresenta elementos linguísticos-textuais e discursivos que permitem identificar as ideologias operadas para construir não só saberes contrários ao parto normal, mas também saberes favoráveis à cesariana, à pedido da gestante, sem indicação clínica.

Itens lexicais com teor negativo como "risco", "verdadeira tortura", "sofrimento", “imposição", “dores", “desnecessário", "anóxia" "morte do bebê", "sequelado", ao longo do texto, estão associados ao parto normal, contrapondo-se a termos de valoração positiva para a cesárea como: "benefício", “desejo", "escolha", “autonomia", "direito", “evolução" e "diminui os riscos", "segurança.", “diminuição da mortalidade materna e da mortalidade infantil".

O problema é que, na rede pública, essa Resolução não é observada, ficando as mulheres submetidas à verdadeira tortura, uma vez que não querem passar pelas dores e pelos riscos de um parto normal, mas não lhes é dada opção. Ademais, como já dito, surpreende saber que até mesmo a analgesia lhes é negada (PL p.2).

Com efeito, muitos são os casos em que, graças à submissão ao parto normal, o concepto vem a sofrer anóxia (falta de oxigênio), ficando sequelado para o resto da vida, em virtude da popularmente chamada paralisia cerebral. Nas situações mais graves, a anóxia leva à morte do bebê, seja dentro do ventre materno, seja alguns dias após o nascimento (PL p. 3). 
Ora, que nome dar à dor imposta à parturiente que, optando pelo parto cesariano, uma vez atendidos os protocolos que garantem a segurança e desenvolvimento do feto, tem sua opção inobservada? (PL p. 3).

A esse respeito, importante lembrar que a história da cesárea se desenvolve paralelamente à diminuição da mortalidade materna e da mortalidade infantil (PL p. 4).

Fairclough (2003) afirma que a categoria analítico-discursivo da avaliação é "sempre parcial, subjetiva e, por isso, ligada a processos de identificação particulares". Nesse sentido, o intuito do Projeto de Lei é apresentado com estruturas linguísticas que expressam o aspecto da avaliação, revelando apreciações e perspectivas da autora, explícitas, sobre o que considera bom ou ruim, ou o que deseja ou não, demonstrando um posicionamento ideológico, em prol do projeto de dominação da via de parto.

A ideia do parto normal como uma ameaça ao bem-estar materno e fetal é construída, em várias dimensões, com modos distintos para operar essa ideologia sendo os mais recorrentes: Dissimulação, Fragmentação, Reificação e Legitimação.

A Dissimulação opera a Ideologia ao ocultar as relações de dominação, utilizando como estratégia o deslocamento contextual de termos e expressões, que consiste em "um termo costumeiramente usado para se referir a um determinado objeto ou pessoa é usado para se referir a um outro, e com isso as conotações positivas ou negativas do termo são transferidas para o outro objeto ou pessoa" (THOMPSON, 2011, p.66). Exemplo disso é o emprego da palavra "autonomia” e de interdiscursos dos movimentos sociais à favor da humanização do parto, potencializando outros efeitos de sentidos. A metáfora empregada, "ganha força", também é um recurso linguístico utilizado a favor do interesse ideológico, conforme demonstrado nos trechos a seguir:

Esse é o intuito do presente projeto de lei, conferir voz às mulheres que, desde sempre, foram caladas pelo sistema e, por incrível que pareça, agora, são caladas por aqueles que costumam se apresentar como defensores dos oprimidos (PL p.2).

Nota-se que, apesar dos elevados números de mortalidade materna, fetal e neonatal, o Brasil ruma na contramão daquele que seria o caminho para alterar (para melhor) este estado de coisas, impondo às parturientes o parto normal (PL p.2).

Nessa perspectiva mais horizontal da Bioética, ganha força o princípio da autonomia. Por óbvio, o médico não abandonará a busca do melhor para seu paciente, porém, precisará considerar os desejos deste, sendo certo que todas as decisões passam pelo pilar do consentimento livre e informado (PL p.1). 
O Projeto de Lei, ao longo do texto, apresenta elementos linguísticos que permitem identificar, claramente, que o mesmo é dirigido à população mais pobre, às usuárias do sistema público de saúde. A autora do PL utiliza o termo “oprimidos” como uma estratégia de interdiscurso, em alusão ao autor Paulo Freire (2011), construindo um raciocínio de libertação entre opressores (grupos que defendem o parto normal) e os oprimidos (mulheres em vulnerabilidade: negras e pobres).

Essa realidade vem de longa data, mas ganha força quando formadores de opinião (artistas, políticos e intelectuais) abraçam a filosofia do parto normal, legitimando sua imposição às mulheres em maior vulnerabilidade (PL p.2).

No próximo trecho apresentado, há também a utilização do recurso linguístico do intertexto para operar a ideologia por meio da Dissimulação com uso da estratégia de deslocamento, evidenciado pelo emprego do enunciado aspeado "a mulher sabe parir e o bebê sabe nascer", jargão típico dos grupos sociais ativistas do parto normal, em uma alteração contextual.

A tentativa de convencer no sentido de que o parto normal deve ser estimulado (imposto) chega ao ponto de grupos entusiastas dizerem que a mãe é mais mãe, quando tem seu filho pelo parto normal e que é mais mãe, quando não sofre nenhum tipo de intervenção externa, dado que "a mulher sabe parir e o bebê sabe nascer" (PL p.3).

A partir da compreensão do conceito de hegemonia proposto por Gramsci (1991) como uma ação que ultrapassa a estrutura econômica e a organização político-social, atuando sobre o modo de pensar e sobre os direcionamentos pragmáticos, ideológicos e culturais da sociedade, é possível afirmar que há no enredo do texto uma luta pela hegemonia da via de parto.

As posições antagônicas são apresentadas por estratégias discursivas que objetivam demarcar os defensores do parto normal como pertencentes à uma classe social privilegiada, que não utiliza a saúde pública, são descritos como "artistas, políticos e intelectuais", são também apresentados no texto como uma ameaça às mulheres e aos interesses dos defensores da cesariana, sem indicação clínica. A autora usa bastante em seu texto a presunção valorativa, pois não deixa claro quem são esses que fazem as mulheres se calarem, ou mesmo qual a relação entre artistas, políticos e intelectuais e o parto normal. A autora argumenta a partir de subentendidos, presunções, vaguidões (esses grupos; algumas pessoas, aqueles) e por uma certa ironia.

Pelo modo de operação da Fragmentação, e estratégia de diferenciação e expurgo do outro, esses indivíduos e grupos são segmentados, descritos, em uns trechos até mesmo de forma irônica, com a construção simbólica de um inimigo, como "formadores de opinião, que não dependem da 
saúde pública”; “entusiastas”; "esses grupos”; “algumas pessoas”; “aqueles”, como demonstrado nos seguintes recortes:

Ocorre que, nos últimos anos, ganhou força entre formadores de opinião (que não dependem da saúde pública) a ideia de que o parto normal e, em especial, o parto natural seriam melhores que a cesariana (PL p.2).

Essa realidade vem de longa data, mas ganha força quando formadores de opinião (artistas, políticos e intelectuais) abraçam a filosofia do parto normal, legitimando sua imposição às mulheres em maior vulnerabilidade (PL p.2).

A autora deste projeto não compreende por qual razão esses grupos não vislumbram violência obstétrica em tal situação (PL p.3).

No entanto, defendem o direito de a parturiente escolher (e ser respeitada) apenas quando a parturiente escolhe o parto normal, ou o parto natural. Quando a parturiente escolhe a cesárea, esses mesmos grupos abandonam o discurso de que a mulher deve ser ouvida e acolhida em seus desejos, presumindo que essa mulher não foi bem informada e esclarecida (PL p.2).

Indague a um entusiasta do parto normal/natural por qual razão essa via de parto é melhor e a resposta será: a mãe se recupera rapidamente, não fica com cicatriz, o bebê tem menos riscos de problemas respiratórios. É verdade! (PL p.6).

A palavra "entusiasta" é utilizada quatro vezes no PL para fazer referência aos atores da sociedade civil que protegem os benefícios do parto normal, demonstrando também um projeto discursivo de caracterizá-los de forma pejorativa, não científica, principalmente, quando comparado com o discurso racional e científico para defesa da cesárea, com o emprego de termos como "estudos" $e$ “casos concretos" para apresentar os argumentos à favor do parto cirúrgico, embora também não cite explicitamente a quê estudos se refere. Os trechos a seguir apontam essa manobra discursiva:

Não há nenhum estudo que correlacione cesárea realizada a pedido da gestante, antes do início do trabalho de parto, com o resultado morte da mãe e/ou morte do concepto. Mas os casos concretos mostram que essas mortes ocorrem, em regra, quando se tenta por horas o parto normal, recorrendo-se à cesárea, quando a situação já se revela insustentável (PL p. 2)

Com efeito, estudos apontam que a taxa crescente de cesarianas, nas últimas três décadas, acompanhou uma significativa diminuição nas taxas de mortalidade materna (PL p. 2).

O elemento discursivo da ciência é utilizado não apenas para legitimar os benefícios da cesariana, mas também para desqualificar o argumento de que o parto normal diminui a mortalidade materna.

A autora do documento utiliza ainda estruturas linguístico-textuais para difundir a premissa de que os altos índices de mortalidade materna, associados ao parto cirúrgico, são um processo 
natural, ou seja, reifica essa naturalização ("sendo inegável”, "tratava-se de um evento comum”), conforme exemplificado a seguir:

Muito se fala nos números alarmantes da cesárea, sem permitir argumentar que tal procedimento, na verdade, implicou uma evolução, sendo inegável que, no passado, as mulheres morriam muito mais de parto do que morrem hoje. Tratavase de evento comum! (PL p.8)

O modo de operação da Ideologia por Legitimação também é identificado no texto e na trama discursiva, por meio das estratégias de universalização, em que condições especificas para indicação da cesariana são apresentadas como gerais, a partir da elaboração de uma cadeia de raciocínio (números alarmantes $=>$ na verdade $=>$ sendo inegável $=>$ morriam muito mais do que hoje $=>$ evento comum) para justificar o conjunto de relações entre os riscos do parto normal e os benefícios da cesariana (racionalização), e de narrativização, com o uso de contextos históricos para legitimar a posição defendida.

De fato, nos casos concretos em que houve morte e ou graves sequelas ao bebê, fica bastante evidente que se a cesárea tivesse sido determinada antes, os sinistros não teriam se verificado. Em outras palavras, a cesárea diminui os riscos para as mães e para os filhos. (PL p. 1)

Durante muito tempo, vigorou, na Bioética, uma relação vertical entre médicos e pacientes. O médico funcionava como detentor do saber e o paciente como receptor deste saber, impossibilitado de participar das decisões referentes à sua própria saúde (PL p. 1).

Ademais, haja vista os riscos que circundam o parto normal, seja ele natural ou não, pode-se dizer que a imposição do parto vaginal finda por violar também o princípio da não maleficência (PL p. 3)

O princípio teórico contemporâneo da Bioética Complexa, que considera crenças, valores e afetividade para avaliar de forma mais ampla processos de tomada de decisão (GOLDIM, 2009), é apresentado no PL como um argumento discursivo para justificar o direito de escolha da mulher para a cesariana, contrapondo-se à relação hierárquica entre médicos e pacientes, revelando uma estratégia de racionalização para Legitimar a ideologia favorável ao parto cirúrgico à pedido da gestante.

Com o desenvolvimento da chamada Bioética complexa, essa relação deixou de ser vertical, tendendo à horizontalidade, podendo o paciente, sem desrespeitar os saberes médicos, participar das tomadas de decisões referentes à sua saúde e à sua própria vida (PL p. 1).

O discurso do Projeto de Lei ainda utiliza-se de exemplos específicos, casos isolados, como o de comprometimentos fetais em partos normais, para induzir à generalização dos desfechos 184 
neonatais em nascimentos, por via vaginal. Assim, opera a Ideologia por Unificação, padronizando determinadas situações como um único fundamento.

Indague a um entusiasta do parto normal/natural por qual razão essa via de parto é melhor e a resposta será: a mãe se recupera rapidamente, não fica com cicatriz, o bebê tem menos riscos de problemas respiratórios. É verdade! Mas esses males são nada perto de um bebê morto por anóxia, ou paralisado por anóxia, mesmo sua mãe tendo clamado pela realização da cesariana (PL p. 9).

Ao manifestar as consequências de ações advindas de parto cesáreo que causam a morte do bebê, a autora, por meio de uma exemplificação patêmica, dramática, (tendo clamado), busca persuadir destinatários sobre a sua proposta humana. Embora concorde com o benefícios de se fazer um parto normal (é verdade!), deslegitima-os por meio da narrativa dramatizada da morte do bebê.

A Unificação como modo geral de operação da Ideologia, com a estratégia de construção simbólica por estandartização, em que um referencial padrão é proposto como fundamento partilhado (THOMPSON, 2011), aparece também no seguinte enunciado extraído do documento, defendendo o projeto de lei como uma ação voltada aos direitos humanos:

Este é um projeto de lei que preserva a vida, a saúde e a dignidade humana, importantíssimos direitos fundamentais (PL p. 8).

Ao defender a autonomia da mulher para a escolha da cesariana, a autora reforça a realidade da nossa sociedade, fortemente tecnocrática, atravessada por uma cultura de medicalização e patologização do corpo feminino, da gestação e do nascimento. Além disso, desconsidera a fragilidade, da maioria da população feminina, do acesso à informação para orientar uma decisão consciente de riscos e benefícios da via de parto.

O discurso normativo-jurídico do PL ignora a necessidade de estratégias de educação em saúde que garantam oportunidade de uma real autonomia das mulheres na escolha consciente e esclarecida da via de parto.

\section{CONSIDERAÇÕES FINAIS}

Realizamos, a identificação dos modos de operação da Ideologia, propostos por Thompson, e a relação dessa com o poder, o discurso, a língua e as práticas sociais na superfície textual da Justificativa do Projeto de Lei nº 435, de 2019, de autoria da deputada estadual de São Paulo, Janaína 
Paschoal, advogada e jurista, filiada ao Partido Social Liberal (PSL), a partir da Análise de Discurso Crítica dessa proposta legislativa.

O documento analisado vai de encontro às evidências científicas, contrariando as orientações e posicionamentos da Organização Mundial de Saúde, Ministério da Saúde e Federação Brasileira de Ginecologia e Obstetrícia. A autora tenta construir um ethos de credibilidade e cientificidade para a sua audiência, de forma a persuadi-los, no entanto se vale de diversas estratégias ideológicas que conduzem a uma naturalização de uma ideia de forma a deslegitimar ironicamente os contrários a sua tese.

Se a proposta legislativa for concretizada, em todo o país, haverá um retrocesso nas condições de saúde da mulher e da criança, com um aumento indiscriminado nas taxas de cesáreas, contrariando as evidências científicas de boas práticas de assistência ao parto e nascimento.

\section{REFERÊNCIAS}

BRASIL. Câmara dos Deputados. $P L n^{o}$. 435/2019. Autora: Deputada Janaina Paschoal (PSL/SP). Garante à gestante a possibilidade de optar pelo parto cesariano, a partir da trigésima nona semana de gestação, bem como a analgesia, mesmo quando escolhido o parto normal. Disponível em: https://www.al.sp.gov.br/propositura/?id=1000262934.

BRASIL. Ministério da Saúde. Projeto Apice On. Brasilia: MS; 2017. p. 23. Disponível em: https://portalarquivos.saude.gov.br/images/pdf/2017/agosto/18/Apice-On-2017-08-11.pdf

DIJK, T. A. V. Discurso e Poder. São Paulo: Contexto, 2008.

FAIRCLOUGH, N. Analysing Discourse: textual analysis for social research. London: Routledge, 2003.

FAIRCLOUGH, N. Discurso e mudança social. Brasília: Editora Universidade de Brasília, 2001.

FAIRCLOUGH, N. Critical discourse analysis. London: Longman, 1995.

FREIRE, Paulo. Pedagogia do oprimido. 50. ed. São Paulo: Paz e Terra, 2011.

GOLDIM, J.R. Bioética complexa: uma abordagem abrangente para o processo de tomada de decisão. Revista da AMRIGS. Porto Alegre, v. 53, n. 1, p. 58-63, jan./mar. 2009. Disponível em: https://www.ufrgs.br/bioetica/complexamrigs09.pdf

KOTTWITZ F, GOUVEIA H.G, GONÇALVES A.C. Via de parto preferida por puérperas e suas motivações. Esc Anna Nery, v. 22, n. 1, p. e20170013, 2018. DOI: 10.1590/2177-9465-EAN-20170013

LEAL M.C., et al. Avanços na assistência ao parto no Brasil: resultados preliminares de dois estudos avaliativos. Cad. Saúde Pública, v. 35, n. 7, p. e00223018, 2019. DOI: 10.1590/0102-311X00223018 
LEAL, M.C. Parto e nascimento no Brasil: um cenário em processo de mudança. Cad. Saúde Pública, v. 34, n. 5, p. e00063818, 2018. DOI: 10.1590/0102-311X00063818

MAGALHÃES, I. Introdução: a Análise de Discurso Crítica. D.E.L.T.A., v. 21, n. Esp., São Paulo: EDUC, 2005, p. 1-11.

MENDONÇA, S.S. Modelos de assistência obstétrica concorrentes e ativismo pela humanização do parto. Civitas. Porto Alegre, v. 15, n. 2, p. 250-271, abr./jun. 2015. DOI: 10.15448/19847289.2015.2.17899

MERIGHI, M.A.B, GUALDA, D.M.R. O cuidado à saúde materna no Brasil e o resgate do ensino de obstetrizes para assistência ao parto. Rev Latino-am Enfermagem, v. 17, n. 2, p. 265-70, 2009. DOI: 10.1590/S0104-11692009000200020.

RAMALHO, V; RESENDE, V.M. Análise de discurso (para a) crítica: o texto como material de pesquisa. Campinas, SP: Pontes Editores, 2011.

RESENDE, V.M.; RAMALHO, V. Análise de discurso crítica. São Paulo: Contexto, 2006.

PEIXOTO, M.E.G; ALENCAR, C. N.; FERREIRA, R. O objeto da ideologia na teoria crítica do discurso. Linguagem em (Dis)curso - LemD. Tubarão, SC, v. 18, n. 1, p. 215-233, jan./abr. 2018. DOI: 10.1590/1982-4017-180112-5917

VEGA, C.E.P., SOARES, V.M.N.; NASR, A.M.N.F. Mortalidade materna tardia: comparação de dois comitês de mortalidade materna no Brasil. Cad. Saúde Pública, v.33, n. 3, 2017. DOI: 10.1590/0102-311x00197315.

THOMPSON, John B. Ideologia e cultura moderna: Teoria social crítica na era dos meios de comunicação de massa. 9. ed. Petrópolis: Vozes, 2011.

TORRES, J.A; et. al. Cesariana e resultados neonatais em hospitais privados no Brasil: estudo comparativo de dois diferentes modelos de atenção perinatal. Cad Saúde Pública, 30 Suppl:S220-31, 2004. DOI: 10.1590/0102-311X00129813 